\title{
Investigation of university students' behaviour in a Heterarchical twitter community
}

\author{
Masami Yoshida ${ }^{1}$
}

Received: 3 August 2020 / Accepted: 25 November 2020/ Published online: 5 January 2021

(C) The Author(s) 2021

\begin{abstract}
We conducted an investigational study of the formulation of the heterarchical online knowledge-based community among university students, which also involved users outside a course. As an exercise in a course, students were assigned to post their opinions regarding global issues on Twitter to connect with social actors. The emerging all connections were collected by Twitter's application programming interface. Dataset was categorised into types of behaviourgraphics, which were styles of online users' individual behaviour, as proposed by Solis. There were 954 tweets by 197 users, and 13 within 20 types of behaviourgraphics were exhibited in the Twitter community. However, students' isolated tweets without any connection occupied $74 \%$ of all tweets. The tweets of social actors counted for merely $14 \%$ of students' tweets, and connections in the community proved to be sparse. Compared with the types of behaviourgraphics in the results of our previous study, we could identify the following problems in students' messages: content without relational cues, inhibition points in the content, lack of communicative behaviour, insufficient consideration of timeline, and lack of likeability. The results indicate the need to cultivate students' sociability skills and their pre-investigation of other communities in order to expand their knowledgebased community. In terms of future studies, we discuss the importance of promoting a bridge to enhance connections with another community.
\end{abstract}

Keywords Online communication · Online learning · Sociability skills · Twitter · University lesson

\section{Introduction}

O'Reilly (2005) introduced the concept of Web 2.0, the second generation of webbased online services, and the term has become widely recognised. Web 2.0 refers to

Masami Yoshida

yoshida-m@faculty.chiba-u.jp

1 Faculty of Education, Chiba University, 1-33 Yayoi Inage, Chiba 263-8522, Japan 
the relational changes between users and their content. In particular, Web 2.0 offers a new way for groups of people to converse and presents an opportunity for them to gather and share information collectively (Solis and Breakenridge 2009, p. 37). As Web 2.0 evolved, users' interactions increased substantially across various social media services and included collaborative information, which has become common in communication. As a dominant social media service, Twitter is known to enhance social interaction in education through interactions outside of the classroom that can have significant instructional value (Dunlap and Lowenthal 2009). Twitter is expected to be a resource that allows students to discover, evaluate and analyse discussions or issues, such as critically analysing and discussing the elements of a debate around a particular topic (Chawinga 2017; Rinaldo et al. 2011; UNESCO 2019).

In contrast to the traditional university classroom environment, information deployed over the Internet and the resultant online learning environment provide a means to connect with social actors outside of a classroom to access new areas of knowledge. Although learning online has advantages as far as expanding students' knowledge, it also has overt differences compared to a physical classroom. One particular change is that, since the number of students' connections in classroom activities follows a Gaussian distribution and the connections among users' messages in social media follow a power-law distribution (Gadepally and Kepner 2015; Pan et al. 2011; Sadri et al. 2020), the distributions of user connections between the two learning environments are different. In the connections under the power-law distribution, a few users have many connections, but the most users stay in sparse connections, leading to the socalled scale-free network that is inhomogeneous in it's the number of connections (Chen et al. 2013). A hub user located in the centre of aggregated users of a cluster affects many connecting users, but the structure also allows an individual user at lower levels feeds back to the hub user. This is the essential characteristics of heterarchical structure which brings together top-down, bottom-up, and peer-to-peer dynamics (Cumming 2016).

Regarding social media, Nielsen (2006) reported a deviation of the connections seen in online communication as a 90-9-1 rule, where $90 \%$ of users are lurkers who never contribute, $9 \%$ of users contribute a little, and $1 \%$ of users account for almost all of the activity. Connections in Twitter's network have also been shown to follow a power-law distribution (Gonzalez et al. 2012; Java et al. 2007; Asur et al. 2011). The major component on Twitter is a group of well-defined smaller communities that are loosely connected (Bhattacharya et al. 2020).

Although there is a deviation of connections and a few active users in social media, a holistic view of communication noted several important types of users who characterise the community and enhance connections (Solis 2010), such as social beacons, tastemakers, influencers, trendsetters and change agents. In other words, examining a few users of these important types is more valuable than measuring the average nature of all of the connections within the socially developed community.

\subsection{Groundswell}

Forrester Research Inc. released a report entitled 'Social Computing' (Charron et al. 2006), which identified a trend of people using online tools to connect in various ways. This trend involved communication through member-driven news sites, social 
networks, user-generated content sites, online tool services and Wikipedia ( $\mathrm{Li}$ and Bernoff 2011, p. 9). The report also showed that a fundamental change in users' behaviour was happening online and defined it as groundswell:

A social trend in which people use technologies to get the things they need from each other instead of from companies. (Li and Bernoff 2011, p. xii).

The concept of the groundswell is similar to that of Web 2.0, and the technology is recognised as just enabler. The groundswell is made powerful by connecting people directly with each other in new ways, almost-always-connected people who have technology in the hand, while recruiting new people to join the community ( $\mathrm{Li}$ and Bernoff 2011, p. 11). Twitter is recognised as a powerful tool for the groundswell (Li and Bernoff 2011, p. x). Communication by tweets lacks the richness of physical interaction but allows for communication across space and time. Kostakos and Venkatanathan (2010) reported the method of the mixture of spatial and trans-spatial communication modalities that ultimately acted as an individuals' platform for social engagement. Therefore, this study attempts to expand the scholarly reach of students on Twitter in addition to classroom learning.

According to the groundswell, social media is based more on personality than on technology (Grizane and Jurgelane 2017). More specifically, people's activities are analysed based on the groundswell tendencies of groups. Thus, in the context of groundswell, it is important to identify users' activities.

\subsection{Behaviourgraphics to analyse each tweet}

In 2007, Forrester Research conducted an applied study on groundswell that analysed users' participation in social media ( $\mathrm{Li}$ and Bernoff 2011, p. 43-47). The method is called social technographics and is applied technographics (Li 2007). Social technographics provide a methodology for surveying users' groups and level of participation in social computing behaviour. The study defined the following seven user groups: creators, conversationalists, critics, collectors, joiners, spectators and inactives (Bernoff 2010). The analysis of social technographics explains how a user changes their participation in the social network based on their level within the group. Although the social technographics approach was a convenient tool to compare the participation of users in online communities, it cannot be used to analyse the effects of increased numbers of users and connections to other communities. Because a user of a higher group level in one community may display behaviour characteristic of a lower group level in another community, there must be a more effective tool to analyse users' behaviour in detail..

While users' needs in social media are becoming diverse, the nature of their behaviour and character are equally varied. Users' behaviours play a critical role in engagement. Solis (2010) analysed the social web, extracted specific activities and proposed indispensable types of individual behaviours by considering the inner mind of online users. Through his investigation, he classified users' behaviours, represented by messages, into types and called these categories behaviourgraphics (Solis 2011, p. 199-201). While social technographics aim to explicate users' level of participation and the groups they belong to, behaviourgraphics examine the characteristics of users' 
avatars in the online environment and their personality on social media (Solis 2010). Certain descriptors such as curators and conversationalists are being used increasingly in behaviourgraphics in this modern information-driven society (Hobson 2011).

\subsection{Types of behaviourgraphics}

Table 1 contains a list of 20 types of behaviourgraphics..

While these methods of Forrester Research used socially known familiar types of users as criteria, these methods of analysis had been applied in many social marketing studies on Twitter. These studies involved cases of various countries, generations, social groups and time, and portrayed various users' activities on Twitter (Bernoff and Li 2008).

Some relevant factors of this study have been reported, such as the frequency of collecting information (Dommett 2019), students' opinion to connect world professionals for their skill development (Hitchcock and Young 2016), understand scholarly community using Twitter metrics (Díaz-Faes et al. 2019), and model of personal learning cycle of students (Ivanova 2009). Besides, various classification types of online users were reviewed and summarised as typology (Brandtzaeg and Heim 2011). However, previous studies were arranged to value users or their competencies, and there are no criteria that can value each tweet of broader users. Also, the analysis from the holistic view with a social graph analysis is limited (e.g. Visvizi et al. 2020). Since behaviourgraphics have proved to identify behaviour differences of a user in different communities by focusing on tweets, we selected behaviourgraphics in this study as a method of higher analytical capabilities. Therefore, this study engages in behaviourgraphics and social media analysis. Simultaneously, we introduce the analysis of particular users and their formulation of connections, and the following likeonomics and brokerage roles theories are used in the discussion. Findings are continuously compared with the results of our previous study to investigate the different type of community.

\subsection{Likeonomics}

The following theory explains the potential reasons why users selected their behaviourgraphics type in a connection. Bhargava suggested that 'building real and meaningful relationships is not the same thing as networking' (Bhargava 2012, pp. 34 35). He succinctly introduced likeonomics, which are the key strategies of conducting messages to increase successful engagement, and explained that users had to be liked to be trusted. He also explained the power of likeability and the following five components that build trust (Bhargava 2012, p. 55-56):

(1) Truth: There is no more important quality than the real truth, and we live in a time where people are more able to demand it than ever. Be transparent and proud of your grassroots.

(2) Relevance: The challenge to be relevant requires that you centre yourself on the world that someone else already cares about.

(3) Unselfishness: If there is one principle that seems dramatically hard to consistently do, it is behaving in an unselfish way. 
Table 1 Types and descriptions of behaviourgraphics (Solis 2011, 199-201)

Types Descriptions

Problem Solvers One of the most common sources of conversations and updates in social media are questions...people seeking information in the hopes that commenters will respond with resolution or direction.

Commenters Providing thoughts, opinions, observations, experiences, and sometimes, unfiltered reactions to the information shared online. They are less likely to produce original content, but are compelled to share their views.

Researchers Peer to peer influence is prominent in social networks, and researchers rely on their social graphs for information and direction to make qualified decisions. They are also active in championing polls and surveys to truly learn about the thoughts and opinions of those connected to them.

Conversationalists Conversationalists fuel threads within and across networks by participating in conversations through proactive updates and direct responses to other content.

Curators Curators work diligently to find and share what captivates them as filtered by what they believe will interest their followers in their interest graphs.

Connectors Individuals who take social networking literally. Connectors represent the most resilient and obliging roles in new media today, constantly investing in the quality and calibre of their networks and the niche works of those important to them.

Producers Among the more elite group of online participants, their stature is earned by the amount of content they generate within multiple networks.

Broadcasters Broadcasters are mostly one-way communicators who either intentionally or unintentionally push information to followers without injecting conversational aspects into the mix.

Marketers

Profiles dedicated to marketing ideas, products, or services and may or may not include content outside of their portfolio, unless the account is focused on funnelling beneficial and value-added solutions to specific audiences regardless of origin.

Entertainers Entertainers feel responsible to satisfy and engage the social graph they weave. They use their channels to delight, occupy, or divert others, and they're often cherished by those who follow them.

Socialites Individuals who have earned varying levels of celebrity, these new Internet famous personae who earn recognition and attention in online networks, which increasingly spills over to real-world fame.

Self-promoters Unlike broadcasters and marketers, self-promoters are unconcealed in their intentions through constant updating of activities, events, and accomplishments.

Egocasters Egocasters contribute to the ego in the egosystem and represent the evolution of self-promoters. What they think and say is what they believe to be the reality for one and for all. They lose touch with perspective, as listening gives way to telling...

Observers Often referred to as inactives, lurkers, or simply consumers, observers represent the majority of the social web today, defined by those who read and also share information in the back channel, including email, and also in the real world.

Social Climbers Social capital is not only something that is earned in social networking, it is something that is proactively pursued by those whose sole mission is to increase influence scores. These individuals intentionally climb ladders on the avatars, profiles, and social capital of others.

TMI

The things some share in social media continue to blur the line between what's relegated to inner monologue versus that for sharing with others in public. The state of sharing "too much information" is dictated by those on the receiving end of the update, not those who publish it.

Spammers 
Table 1 (continued)

Types
$\begin{aligned} & \text { Descriptions } \\ & \text { Those accounts and profiles that are created to push messages blindly. They're often tied } \\ & \text { to current events (using trending keywords or hashtags) or targeting influential voices } \\ & \text { to lure them into clicking through to their desired goal. } \\ & \text { Not included in the graph, but an important category to recognise as leachers take the } \\ & \text { good work of others and channel it into their own accounts almost exclusively for the } \\ & \text { sake of promoting their cause. } \\ & \text { Wheachers } \\ & \text { en we love something, we tell a few people. When something bothers us, we tell } \\ & \text { their social stream. And, as customer service takes to the Social Web, these } \\ & \text { complainers are only encouraged to share their experiences to achieve satisfaction and } \\ & \text { earn recognition for their role as the new social customer. } \\ & \text { Certainly the bottom of the connected customer psychology chart, these individuals exist } \\ & \text { solely to suck the life out of engagement. These social vampires jump from thread to } \\ & \text { thread and profile to profile and community to community, feeding on the animation } \\ & \text { and productivity within each. While everyone is left void of intellectual or emotional } \\ & \text { resolve, trolls leave with a greater sense of self-worth. They are not worthy of } \\ & \text { engagement. }\end{aligned}$
Trolls

(4) Simplicity: This has near universal agreement from leading thinkers in the world about its importance. Keep your message simple and keep people's interested.

(5) Timing: We will look at the examples of how people are always at the heart of timing. Understanding when to push your idea is the crucial factor that can help ensure success.

\subsection{Brokerage roles}

When a community involves users who need to connect with another community, brokerage roles dominate the development of the former community. When a broker emerges, individual positions in the community are characterised depending on the dominant type of brokerage. Gould and Fernandez (1989) outlined the following five distinct types of brokers in online communities, which are illustrated in Fig. 1. In a triad, a node of broker B mediates a transaction between two nodes from one or two groups (Lee and Sohn 2015, p. 88).

(6) Coordinator: A mediating user who transfers a message to another member.

(7) Representative: A user representing the entire cluster/community; they transfer a message to another cluster/community.

(8) Gatekeeper: A user who accepts a message from another cluster/community and transfers it to his/her own cluster/community.

(9) Itinerant broker: A user located in a different cluster/community who connects users within the same cluster/community. 
(10) Liaison: A user who connects users of different clusters/communities and transfers the messages beyond his/her own cluster/community.

(Fig. 1 around here)

Brokerage roles explain the particular users who bridge connections between groups or communities, and contribute to understand the holistic view and depict integral functions of tweets..

\section{Materials and method}

This study monitored and analysed the activities of university students on Twitter through assignments in a course. Before beginning the study, researchers explained to the students that their tweets would be recorded and used analysed, and all of them agreed to participate.

- Subject course: A university course. A general education subject to learn world issues using online database

- Target students: 65 first-year undergraduates from three departments (literature, engineering and nursing).

- Media skills and online experiences of students: All students own PCs and smartphones, use social media in their daily lives and consider themselves to be netizens and digital natives.

- All students had finished a preceding training course to master cybersecurity, safety skills, and knowledge. Also, at the beginning of the course, students were shown how to make additional pseudonyms on Twitter available to use in the course.

- Twitter's application programming interface was used to collect Twitter communication data by NodeXL Pro, which is an extendible toolkit for community exploration, data collection, and analysis. NodeXL calculated metrics which were used to describe networks.

- The collected dataset used in the analysis of this study involves all attributes of tweets, such as tweet types, time, user profiles, language settings, and numbers of followers.

- All tweets in the dataset were classified into behaviourgraphics types by the author without problems.

- Course period: October-December 2019 (nine weeks)

- Course outline: The course involved the following five sessions, wherein the students were to learn about global issues:

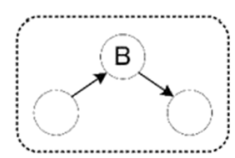

coordinator

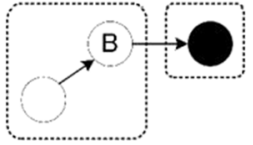

representative

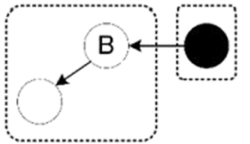

gatekeeper

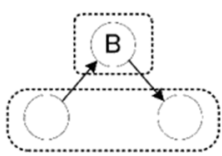

itinerant broker

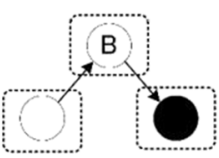

liaison

Fig. 1 Five brokerage roles of node B 
(1) Economic situation

(2) Poverty

(3) Disparity

(4) Urban problems

(5) Water and sanitation

While the effects of using Twitter in a university course were tangible, allowing both for an exchange of viewpoints, collaboration, clarifications and communications regarding course content and for the sharing of resources and experiences with the public (Warren and Wakefield 2013, p. 104), all students in this study were asked to post their opinions about the course material (specific global issues) on Twitter after each session in order to form a connection with a social actor. The students understood social interaction and connections were fundamental to the course.

Students were permitted to tweet as many times as they wanted beyond the two required tweets per session. Students were allowed to post isolated tweets, replies (i.e., tweets through which a student responds to another user's tweet), quote retweets (i.e., retweets with a comment to another user's original tweet) or mentions (i.e., tweets that contain another user's account name). They were also able to add hashtags to indicate keywords or topics they wished to communicate in a tweet. To identify all of the connections that emerged from the course, all students were required to use a specific lesson hashtag in their tweets.

\section{Results}

Ultimately, the study involved 197 Twitter users comprised of 65 students, 112 social actors, 10 dropout students, and 10 students outside of the course (Table 2).

Since the Twitter follower network demonstrates power-law distribution, the users' numbers of followers are represented by the median. The median number of students' followers was 4.5 and the median number of followers of the social actors deployed was 1195 . This is because $89 \%$ of students used pseudonyms, and their profiles were blank, as they had limited communication experiences under these pseudonyms.

The 954 tweets collected were categorised into types of behaviourgraphics. Of the 20 total types of behaviourgraphics, 13 appeared in the community (Table 3).

An isolated tweet self-loop, meaning the tweet had no reply from others and no relation to another tweet in message description, occurred with $74 \%$ of tweets. Regarding types of

Table 2 Users in the Twitter community

\begin{tabular}{lll}
\hline Twitter Users & Number & Median Followers \\
\hline Students who performed all assignments & 65 & 4.5 \\
Students who had withdrawn from the course & 10 & 15 \\
Students not in the course & 10 & 260 \\
Social actors & 112 & 1195 \\
\hline
\end{tabular}

Note: Student not in the course $=$ Students identified from user profiles and posted tweets who were attending in the same university, but were not in the course 


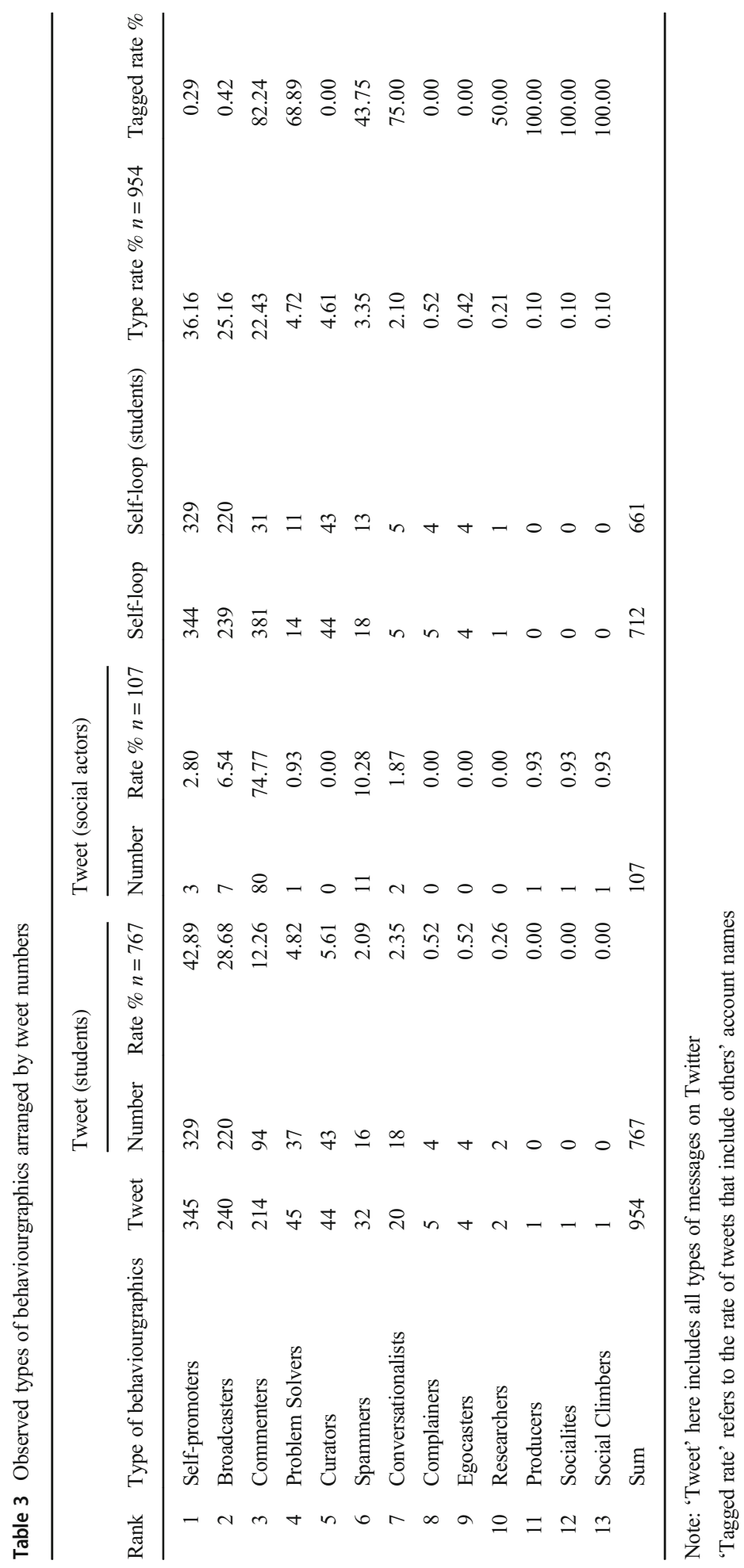


behaviourgraphics, students posted a considerable number of tweets in the categories of selfpromotors, broadcasters and commenters, and $84 \%$ of all tweets fell under these types. In addition, these three types represent the typical basic function of Twitter - for individuals to express their opinions. This meant there was limited communicative contact between students and social actors. Furthermore, a few of the tweets that made up tweets from social actors to students included the lesson hashtag, and they amount to about $14.0 \%$ of the number of students' tweets. The number of average connections of students with a social actor was also small (1.23 connection per social actor). Further, using the 90-9-1 rule, it could be estimated that there were many inactive types, such as observers and leachers, who were not involved in the data.

Unfortunately, none of the behaviourgraphics types that appeared in the study related to community management, and this verified the sparseness of the connections. Motivating social actors to interact more with students would be the surest path to increasing success in community development.

\subsection{Behaviourgraphics and tweets}

Next, the relationship between Twitter message types and types of behaviourgraphics was analysed (Table 4).

Self-promotors, a group which refers to students whose tweets do not include available information and communicative concern, accounted for 50\% of students' tweets; this was the least strategic and sometimes most self-satisfied approach, and this group simply followed the basic function of tweets. Rich information tweets by

Table 4 Twitter message type and behaviourgraphics

\begin{tabular}{|c|c|c|c|c|c|c|c|c|c|}
\hline \multirow[b]{2}{*}{ Rank } & \multirow[b]{2}{*}{$\begin{array}{l}\text { Type of } \\
\text { behaviourgraphics }\end{array}$} & \multicolumn{2}{|l|}{ Tweet } & \multicolumn{2}{|l|}{ Retweet } & \multicolumn{2}{|c|}{ Replies to } & \multicolumn{2}{|l|}{ Mentions } \\
\hline & & Students & $\begin{array}{l}\text { Social } \\
\text { actors }\end{array}$ & Students & $\begin{array}{l}\text { Social } \\
\text { actors }\end{array}$ & Students & $\begin{array}{l}\text { Social } \\
\text { actors }\end{array}$ & Students & $\begin{array}{l}\text { Social } \\
\text { actors }\end{array}$ \\
\hline 1 & Self-promoters & 329 & 2 & 0 & 1 & 0 & 0 & 0 & 0 \\
\hline 2 & Broadcasters & 220 & 6 & 0 & 1 & 0 & 0 & 0 & 0 \\
\hline 3 & Commenters & 29 & 0 & 35 & 78 & 26 & 1 & 4 & 1 \\
\hline 4 & Problem Solvers & 11 & 0 & 0 & 1 & 20 & 0 & 6 & 0 \\
\hline 5 & Curators & 43 & 0 & 0 & 0 & 0 & 0 & 0 & 0 \\
\hline 6 & Spammers & 13 & 2 & 0 & 2 & 3 & 5 & 0 & 2 \\
\hline 7 & Conversationalists & 5 & 0 & 0 & 2 & 13 & 0 & 0 & 0 \\
\hline 8 & Complainers & 4 & 0 & 0 & 0 & 0 & 0 & 0 & 0 \\
\hline 9 & Egocasters & 4 & 0 & 0 & 0 & 0 & 0 & 0 & 0 \\
\hline 10 & Researchers & 1 & 0 & 0 & 0 & 1 & 0 & 0 & 0 \\
\hline 11 & Producers & 0 & 0 & 0 & 0 & 0 & 1 & 0 & 0 \\
\hline 12 & Socialites & 0 & 0 & 0 & 1 & 0 & 0 & 0 & 0 \\
\hline \multirow[t]{2}{*}{13} & Social Climbers & 0 & 0 & 0 & 1 & 0 & 0 & 0 & 0 \\
\hline & Sum & 659 & 10 & 35 & 87 & 63 & 7 & 10 & 3 \\
\hline
\end{tabular}

Note: 'Tweet' here refers to an anonymous target message on Twitter 
students, shown by the types; curators, researchers, broadcasters and problem solvers, constituted another $42 \%$ of tweets. These types of behaviourgraphics communicate through information and are recognised as being used just for practical reasons (Johnson and Kulpa 2007). Few students intentionally used information written by social actors in their tweets; mentions, which reflected their lower engagement.

Most of the social actors' tweets were characterised by the commenters type in retweets, and this accounted for $73 \%$ of their tweets. Unfortunately, as far as interactive tweets, replies to appeared in only seven tweets from social actors, and five replies to were messages from spammers. This passive engagement proved insufficient to enhance this knowledge-based community.

\subsection{Communication between students and social actors}

Figure 2 shows the ranking graph of behaviourgraphics types by the number of tweets, and the number of self-loop tweets. The areas between the two lines indicate tweets with connections.

In the holistic view of the types of communications, commenters, problem solvers and conversationalists used were identical in this community.

To further investigate tweets which involved connections between students and social actors, such tweets were summarised by types of tweets and types of behaviourgraphics (Table 5). Self-loops were excluded from the data, and the ranking of the behaviourgraphics is changed from Table 4. Within the types of behaviourgraphics, higher rates of connections were seen in producers, socialites and social climbers (see Table 3), and these types of tweets were identical to those written

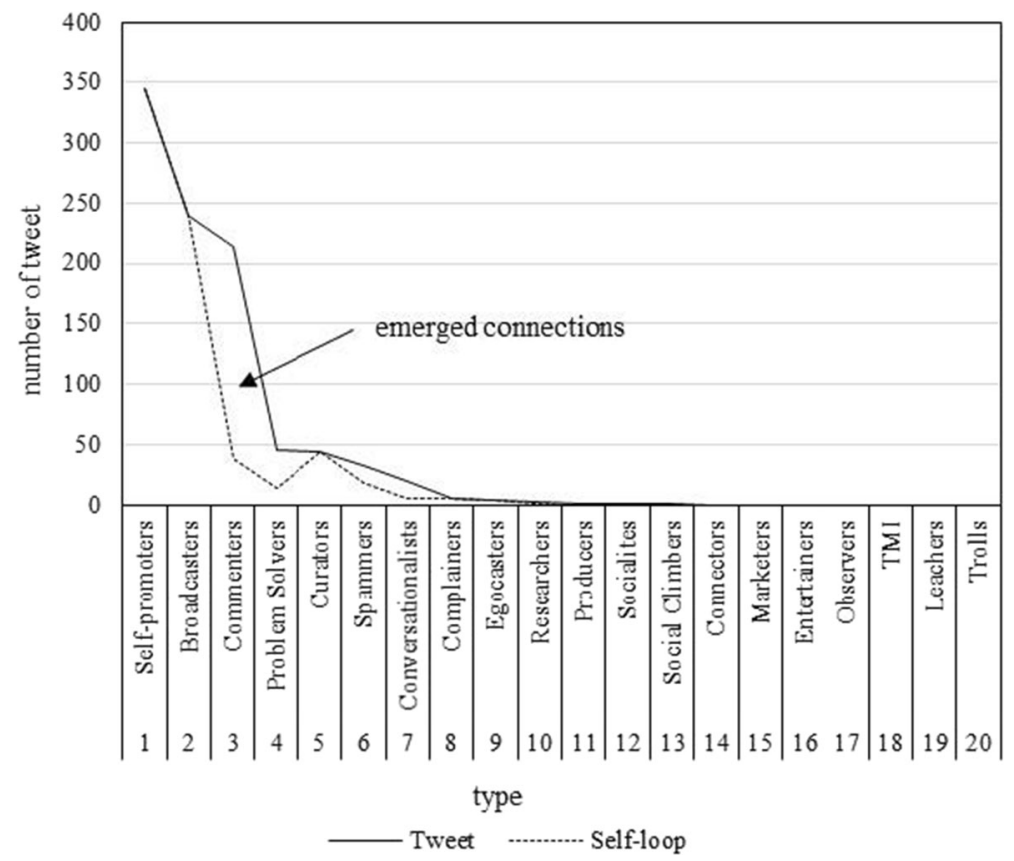

Fig. 2 Ranking number of tweets by type of behaviourgraphics 
Table 5 Types of behaviourgraphics with connections between students and social actors by types of tweets

\begin{tabular}{|c|c|c|c|c|c|c|c|c|}
\hline \multirow[b]{2}{*}{ Rank } & \multirow[b]{2}{*}{ Type } & \multicolumn{2}{|l|}{ Retweet } & \multicolumn{2}{|c|}{ Replies to } & \multicolumn{2}{|l|}{ Mentions } & \multirow[b]{2}{*}{ Sum } \\
\hline & & Students & Social actors & Students & Social actors & Students & Social actors & \\
\hline 1 & Commenters & 8 & 76 & 24 & 0 & 4 & 1 & 113 \\
\hline 2 & Problem Solvers & 0 & 1 & 20 & 0 & 6 & 0 & 27 \\
\hline 3 & Conversationalists & 0 & 2 & 13 & 0 & 0 & 0 & 15 \\
\hline 4 & Spammers & 0 & 0 & 2 & 3 & 0 & 2 & 7 \\
\hline 5 & Self-promoters & 0 & 1 & 0 & 0 & 0 & 0 & 1 \\
\hline 6 & Broadcasters & 0 & 1 & 0 & 0 & 0 & 0 & 1 \\
\hline 7 & Researchers & 0 & 0 & 1 & 0 & 0 & 0 & 1 \\
\hline 8 & Producers & 0 & 0 & 0 & 1 & 0 & 0 & 1 \\
\hline 9 & Socialites & 0 & 1 & 0 & 0 & 0 & 0 & 1 \\
\hline \multirow[t]{2}{*}{10} & Social Climbers & 0 & 1 & 0 & 0 & 0 & 0 & 1 \\
\hline & Sum & 8 & 83 & 60 & 4 & 10 & 3 & 168 \\
\hline
\end{tabular}

by social actors. This showed the valid sociability of social actors, although the numbers of these types of tweets were small.

Although students' tweets to other users involved a higher number of replies to (77\% of connections), more tweets of social actors were classified in the category of retweet ( $92 \%$ of connections). This shows the different levels of engagement of users' groups and the more casual concerns of social actors. While the results for social actors covered all 13 types of behaviourgraphics, the results for students involved only five dominant types.

Concerning the success of connections, especially the factors of information that appeared in students' tweets, Bhargava (2012, p. 49-50) reported four inhibition ways from the study of likeonomics that render messages meaningless:

(1) Statistical insignificance.

(2) Wishful extrapolation: a conclusion from data that is based more on wishful thinking than on actual data.

(3) Inconclusive conclusions: a slight leaning toward a finding is often used as proof of a certain finding.

(4) Planning paralysis: making conclusions based on inconclusive data.

The ways explain notices for online users to boost their connections, including building trust or confidence (Veronica et al. 2018). The first three inhibition ways often appeared in the tweets of self-promotors and broadcasters because the students were novices in the area of global issues. This resulted in a lower rate of connections in Fig. 2.

The following statements, tweeted by students, are cases of inhibition ways (the original messages were written in Japanese and translated by the author of the present study). 
- I investigated the poverty rate of Africa, and it fluctuated for years and was unstable. While African countries do not establish their own economic policies, they need to stabilise the government and promote direct investment of other foreign companies.

(Wishful extrapolation: A student should do considerably more data analysis to select and propose a measure for the poverty issue.)

- Installation of water and sewer systems is urgent in Asia and Africa. Clean water resources and solid sewage treatment are directly related to saving lives. The development of wells for irrigation is secondary.

(Inconclusive conclusions: In some countries, irrigation is more important for people's life, job activities and safety living.)

- If income redistribution reduces inequality and increases social and economic stability, crime, anti-social behaviour, and the effort spent on the prevention of such crimes will be put toward productive activities. These things will lead to an increase in economic growth.

(Wishful extrapolation: There are many theories that slight disparity introduces positive effects on economic growth.)

Commenter types had a higher rate of connections with social actors (69\% of students), and it was a better strategy for students to provide comments than to provide information.

\section{Discussion}

We used behaviourgraphics to understand the student as a person digitally empowered to use knowledge as a resource of activity. In fact, knowledgebased activities are part of identity creation. In the heterarchical Twitter community, there was no organiser in the emerging community, the questions in a course are under less control, indicating a loss of authority and therefore a loss of some degree of the teacher's influence. This is predicted by the advent of groundswell and enabled by Web 2.0 technology.

What follows allows teachers to better understand the extent to which students can reach, communicate and influence social actors. The use of social media in universities is framed by students and online users external to the internal course aim, but due primarily to communications and information technology, course boundaries have become much more fluid, to the extent that students now help to create and sustain the course.

\subsection{Comparison of communities}

In our previous study, we investigated another genre of matured community, the music fanbase of entertainment users' communication, and the data were compared with the knowledge-based community in the present study. In our study of the music fanbase community, 4040 messages by 1308 users appeared during 16 months of online communication (Yoshida and Thammetar 2015). 
When the top-ranking rate of behaviourgraphics types, which account for over 5\% of tweets from the two communities, are extracted and drawn in a radar chart (Fig. 3), dominant types of behaviourgraphics appear to be quite different. The dotted line in the figure shows the tagged rate of this study. On the one hand, the results showed that the types selected by students did not allow for connections with social actors. A higher rate of making connections with other users appeared in the commenters and conversationalists types in the music fanbase community, and unexpectedly, these types had higher rates of making connections in the present study as well. This coincidence implies the following two things: 1) in the initial stage of a new online community, users operate by way of a self-interested and isolated messaging strategy and 2) after a community is developed, users turn to a communicative and altruistic messaging strategy.

The Twitterverse, which is the social network of all users on Twitter, often drifts from topic to topic over time, where the interests of users swing among different subtopics of a more general topic or particular aspects of the topic become more popular than other aspects (Albakour et al. 2013). The drift is due to the communicative characteristics involved in expanding the community. The fanbase's conceptual image of the message line in Fig. 4 explains the importance of following the flow of interests in the community. This implies that when a student composes a tweet or finds additional hashtags allowing their tweet to appear in the filtering results of a social actor, the student also needs to take into account the balance between showing interest in emerging subtopics and expressing interest in the overall topics of the community. In fact, in our data, students' self-initiated messaging covered different topics together in the timeline (the left image in Fig. 4).

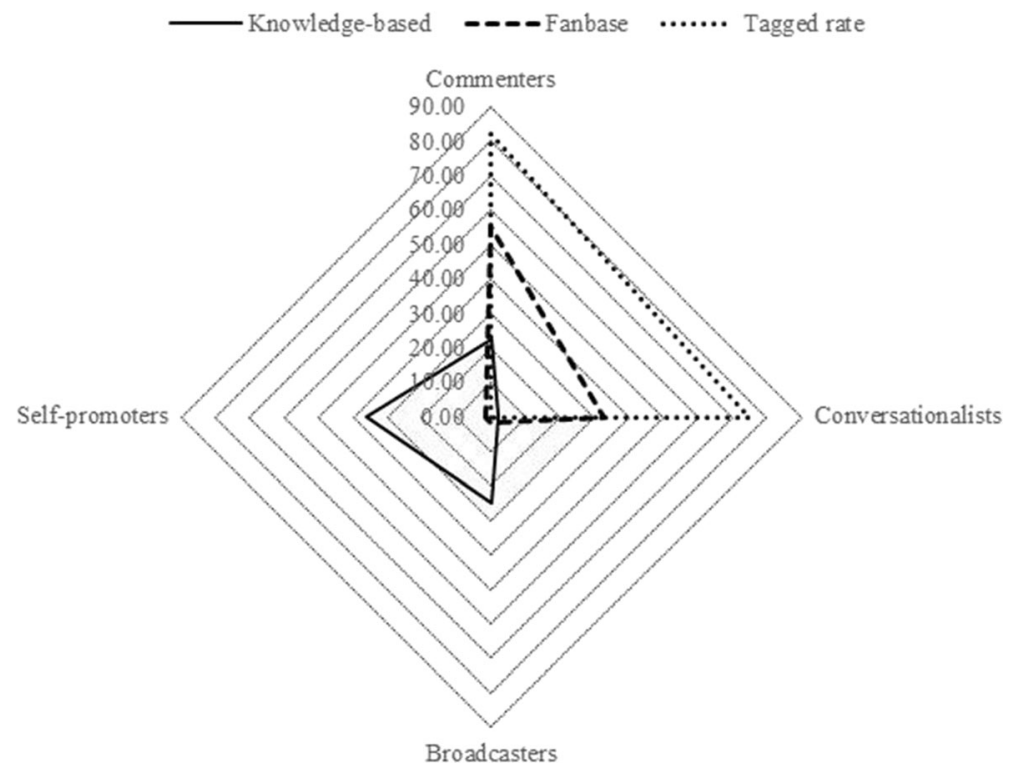

Fig. 3 Radar chart to compare the knowledge-based community in this study and the fanbase community in the previous study. The selected types of behaviourgraphics make up more than $5 \%$ of the behaviourgraphics type rate 


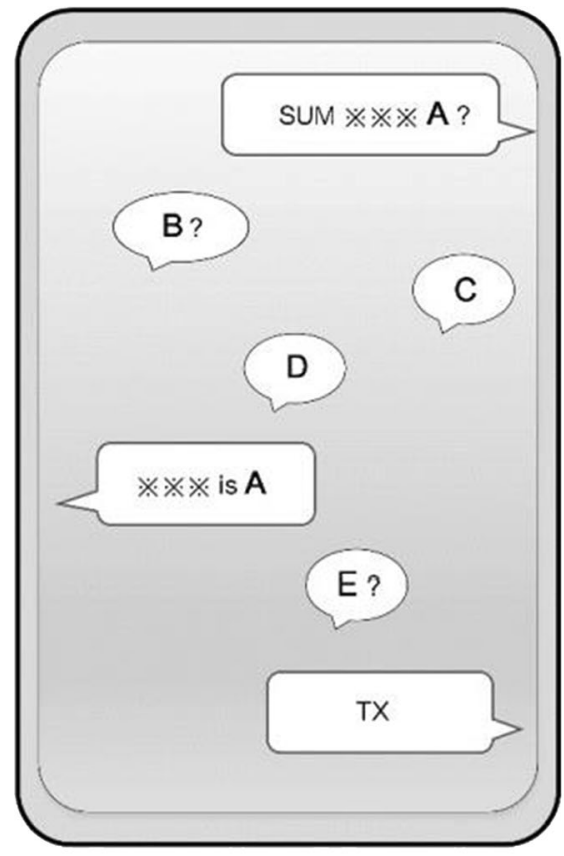

Knowledge-based

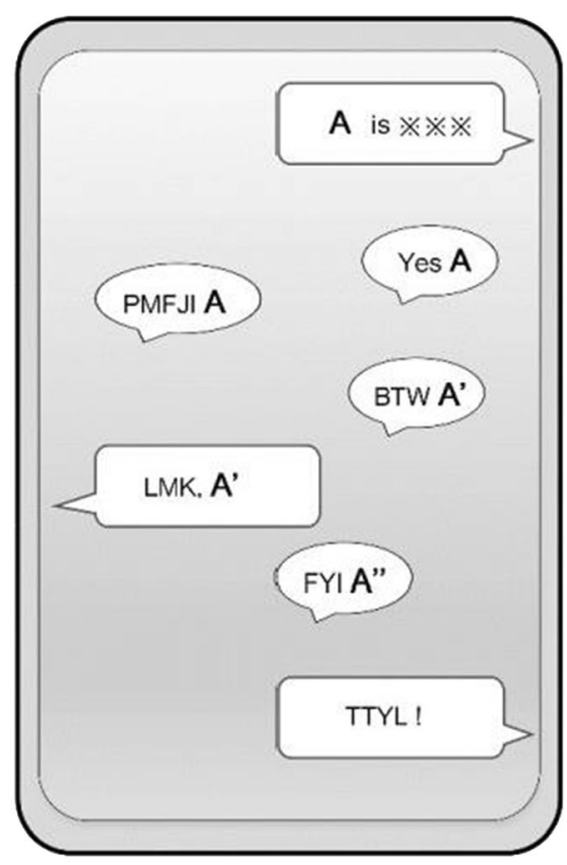

Fanbase

Fig. 4 Conceptual images of different environments - knowledge-based and fanbase

\subsection{Likeonomics}

Lack of (3) unselfishness of likeonomics explains the lower tagged rate of connection for broadcasters and self-promotors in Figs. 2 and 3. Students' blank profiles led to problems in (1) truth. Tweets posted by students in the community without consideration of context could not capture and utilise topic drift, thereby showing insufficient (2) relevance. Furthermore, many students could not adapt their tweets to match the (5) timing of discussions in other communities of social actors. Likeonomics is also useful for developing students' sociability skills.

The following case shows successful knowledge connections, including all principles of likeonomics, and unsuccessful topic drift from connections, to show the inexperience of the community of this study. Before posting the following tweet, a student tweeted her opinions regarding certain global issues. Simultaneously, she increased her Twitter presence by amassing followers and retweets. Then, a series of tweets developed by way of replies to a famous civil activist in Mongol. The student's message was written in Mongolian, and she focused on the undeveloped wastewater regulation of Mongolia. (The author of this study translated the following tweets.)

- Student asks: How are you? I want to ask you something. Is there an establishment of the law for Ger area toilets? Is it possible to promote bio-toilets within the law?

- A human right activist 1 replies: It is in the law on waste. 
- Continuously, a civil society activist 2 replies: Waste law 10.3.6. Business entities and organisations shall establish soil polluting latrines; Forbidden. There is no legal regulation to hold citizens accountable.

While this student was able to achieve likeonomics and receive replies, she was unable to develop continuous communication. She should instead have tweeted a comment on Mongolia's lack of regulation to establish a drifting topic. In this regard, knowledgebased communication requires more consideration and strategic preparation than music fanbase communication, in which users already understood one another in the same context.

In conclusion, these results showed the need to cultivate students' sociability skills and pre-investigation of communities. This will allow them to find interesting subtopics of target community to be able to design more tweets of commenters and conversationalists types in order to expand their knowledge-based community.

\section{Future study}

This study's results in terms of creating and responding to knowledge-based communication highlight the fact that current students' online performance is insufficient because they do not understand or connect with other online communities.

The social presence theory is one pedagogical view that describes a way of thinking about social connections and interactions for student engagement online (Garrison et al. 1999). Social presence measures the feeling of community that a learner experiences in an environment that explores both media and the sociocultural construction of knowledge (Tu and Marina McIsaac 2002). A recent study of social presence theory described how desirable personal, social and psychological traits facilitate trust (Lu et al. 2016). The theory explained the effects of learning in matured sociocultural communities. However, related studies were executed under teacher-guided communication, and none of these studies found recommendations to help students connect with other communities in the initial stage of the community's development.

Connectivism, another pedagogical theory, emphasises the importance of making connections for observing how information is disseminated in a knowledge-based community (Siemens 2006). The theory also explains the importance of students making connections with subject-related experts in other online communities, but the concrete technical idea of what it is to make a connection with an expert remains unexplored. The relationship of both theories with our study implies the future study to analyse students' social activities into the pedagogical monitoring system, such as learning analytics.

The present study explored the problems the new community faced and investigated the various approaches students in the community took to respond to these challenges. The resulting behaviourgraphics types did not include communicative types, such as connectors and entertainers, who bridge connections across the community. While students in the community worked to fulfil their course tasks, they acted as instrumental users, practicing, for example, information acquisition, low entertainment usage, a high score on PC and Internet usage in general, and good ICT access and a higher educational level (Heim and Brandtzæg 2007). Furthermore, they acted as attention 
seekers who craved attention and comments from others (OFCOM 2008, p. 29), but most of them failed to connect with social actors.

In our previous studies, we detected the appearance of coordinator and gatekeeper brokers during the development of a community of schoolteachers on Twitter (Yoshida and Thammetar 2017). The findings implied that it was easy to introduce brokers from peer communication among students in the same community and that it was important to monitor the context of the community so that it corresponded with interests of members, which were also observed in the results of the present study.

However, the introduction of a representative broker requires acceptance by another community. In our previous case of the music fanbase, we were able to confirm the emergence of a representative broker, and both communities had contextual similarities. This suggests the need for students to conduct preinvestigation on Twitter. Additionally, while users in the knowledge-based community swing between different subtopics and show potential topic drift, this should be regarded as likeonomics, especially because trust is essential for the sociability skill of a broker. Furthermore, students can improve their profiles to better adapt to the context of the community.

Both itinerant and liaison brokers require a potential drive to be a broker in another community in order to access or respond to students. Concerning this drive, Solis (2011, p. 199) explained that active behaviourgraphics were based on benevolence, that is, unselfish and kind-hearted behaviour that earns the goodwill of other people. This benevolence is required for a person to become a broker in social networking with a purpose, mission and genuine intent to grow communities based on trust, vision and collaboration. These characteristics would be key if a student's expected social actor was a broker.

As we have confirmed the behaviours and issues of students on Twitter, we intend in our further studies to clarify the process of broker emergence. Fortunately, many of the students were interested in global education and we intend to introduce further activities on Twitter after the course in order to apply their learning into their daily lives.

Acknowledgments This work was supported by Japan Society for the Promotion of Science, KAKENHI, Grant-in-Aid for Challenging Research (Pioneering), Grant Number 20K20512.

Funding JSPS, Grant-in-Aid for Challenging Research (Pioneering).

Data availability Not applicable.

\section{Compliance with ethical standards}

Conflicts of interest/competing interests No conflict of interest and no competing interests was reported by the author.

Code availability Not applicable. 
Open Access This article is licensed under a Creative Commons Attribution 4.0 International License, which permits use, sharing, adaptation, distribution and reproduction in any medium or format, as long as you give appropriate credit to the original author(s) and the source, provide a link to the Creative Commons licence, and indicate if changes were made. The images or other third party material in this article are included in the article's Creative Commons licence, unless indicated otherwise in a credit line to the material. If material is not included in the article's Creative Commons licence and your intended use is not permitted by statutory regulation or exceeds the permitted use, you will need to obtain permission directly from the copyright holder. To view a copy of this licence, visit http://creativecommons.org/licenses/by/4.0/.

\section{References}

Albakour, M., Macdonald, C., \& Ounis, I. (2013). On sparsity and drift for effective real-time filtering in microblogs. In proceedings of the 22nd ACM international conference on Information \& Knowledge Management. San Francisco: California. https://doi.org/10.1145/2505515.2505709.

Asur, S., Huberman B, A., Szabo G., \& Wang C. (2011). Trends in social media: Persistence and decay. SSRN Electronic Journal, https://doi.org/10.2139/ssrn.1755748.

Bernoff, J. (2010). Social technographics: Conversationalists get onto the ladder. Forrester Research, Inc. https:/forrester.typepad.com/groundswell/2010/01/conversationalists-get-onto-the-ladder.html. Accessed June 52012.

Bernoff, J., \& Li, C. (2008). Groundswell: Winning in a world transformed by social technologies. MA: Harvard Business School Press.

Bhargava, R. (2012). Likeonomics: The unexpected truth behind earning trust, influencing behavior, and inspiring action. Hoboken, NJ: John Wiley \& Sons.

Bhattacharya, S., Sinha, S., \& Roy, S. (2020). Impact of structural properties on network structure for online social networks. Procedia Computer Science, 167, 1200-1209. https://doi.org/10.1016/j.procs.2020.03. 433.

Brandtzaeg, P. B., \& Heim, J. (2011). A typology of social networking sites users. International Journal of Web Based Communities, 7(1), 28-51.

Charron, C., Li, C., \& Favier, J. (2006). Social computing: How networks erode institutional power, and what to do about it. Cambridge, MA: Forrester.

Chawinga, W, D. (2017). Taking social media to a university classroom: Teaching and learning using twitter and blogs. International Journal of Educational Technology in Higher Education, 14, no.3. https://doi. org/10.1186/s41239-017-0041-6.

Chen, K. C., Chiang, M., \& Poor, H. V. (2013). From technological networks to social networks. IEEE Journal on Selected Areas in Communications, 31(9), 548-572.

Cumming, G. S. (2016). Heterarchies: Reconciling networks and hierarchies. Trends in Ecology \& Evolution, 31(8), 622-632.

Díaz-Faes, A. A., Bowman, T. D., \& Costas, R. (2019). Towards a second generation of 'social media metrics': Characterizing twitter communities of attention around science. PLoS One, 14(5), e0216408.

Dommett, E. J. (2019). Understanding student use of twitter and online forums in higher education. Education and Information Technologies, 24(1), 325-343.

Dunlap, J. C., \& Lowenthal, P. R. (2009). Tweeting the night away: Using twitter to enhance social presence. Journal of Information Systems Education, 20(2), 129-136.

Gadepally, V., \& Kepner, J. (2015). Using a power law distribution to describe big data. IEEE, https://doi.org/ 10.1109/HPEC.2015.7322459.

Garrison, D. R., Anderson, T., \& Archer, W. (1999). Critical inquiry in a text-based environment: Computer conferencing in higher education. The Internet and Higher Education, 2(2-3), 87-105.

Gonzalez, J, E., Low, Y., Gu, H., Bickson, D., \& Guestrin, C. (2012). Powergraph: Distributed graph-parallel computation on natural graphs. Paper presented at the 10th USENIX symposium on operating systems design and implementation (OSDI '12). Hollywood, CA. https:/www.usenix.org/system/files/ conference/osdi12/osdi12-final-167.pdf.

Gould, R. V., \& Fernandez, R. M. (1989). Structures of mediation: A formal approach to brokerage in transaction networks. Sociological Methodology, 19, 89-126.

Grizane, T., \& Jurgelane, I. (2017). Social media impact on business evaluation. Procedia Computer Science, 104, 190-196. https://doi.org/10.1016/j.procs.2017.01.103. 
Heim, J., \& Brandtzæg, P. B. (2007). Patterns of media usage and the non-professional users. Paper presented at the CHI 2007 workshop: Supporting non-professional users in the new media landscape, as part of the SIGCHI conference on human factors in computing systems. San José: CA.

Hitchcock, L. I., \& Young, J. A. (2016). Tweet, tweet!: Using live twitter chats in social work education. Social Work Education, 35(4), 457-468.

Hobson, N. (2011). Behaviorgraphics: Better understanding of levels of engagement. Resource document. Industry Dive. https:/www.socialmediatoday.com/content/behaviorgraphics-better-understanding-levelsengagement. Accessed March 52020.

Ivanova, M. (2009). From personal learning environment building to professional learning network forming. Paper presented at the 5th International Science Conference. eLearning and Software for Education, Bucharest. https://www.ceeol.com/search/article-detail?id=38761.

Java, A., Song, X., Finin, T., \& Tseng, B. (2007). Why we twitter: Understanding microblogging usage and communities. Paper presented at the 9th WebKDD and 1st SNA-KDD 2007 workshop on web mining and social network analysis. San Jose, CA. https://doi.org/10.1145/1348549.1348556.

Johnson, G. M., \& Kulpa, A. (2007). Dimensions of online behavior: Toward a user typology. Cyberpsychology \& Behavior, 10(6), 773-780.

Kostakos, V., \& Venkatanathan, J. (2010). Making friends in life and online: Equivalence, micro-correlation and value in spatial and transpatial social networks. Paper presented at the 2010 IEEE second international conference on social computing, Computing, Minneapolis, MN. https://doi.org/10.1109/SocialCom.2010. 181.

Lee, H., \& Sohn, I. (2015). Fundamentals of big data network analysis for research and industry. Hoboken, NJ: John Wiley \& Sons.

Li, C. (2007). Mapping participation in activities forms the foundation of a social strategy. In Social technographics. Cambridge, MA: Forrester http://www.cbpp.uaa.alaska.edu/afef/mapping participation_in_activit.htm. Accessed April 182018.

Li, C., \& Bernoff, J. (2011). Groundswell, expanded and revised edition: Winning in a world transformed by social technologies. Boston, MA: Harvard Business School Publishing.

Lu, B., Fan, W., \& Zhou, M. (2016). Social presence, trust, and social commerce purchase intention: An empirical research. Computers in Human Behavior, 56, 225-237.

Nielsen, J. (2006). Participation inequality: Encouraging more users to contribute. Nielsen Norman Group: Resource document https://www.nngroup.com/articles/participation-inequality/. Accessed November 16 2015.

O'Reilly, T. (2005). What is Web 2.0. Resource document. Newton, MA: O'Reilly Media https://www.oreilly. com/pub/a/web2/archive/what-is-web-20.html. Accessed December 312005.

OFCOM. (2008). Social networking: A quantitative and qualitative research report into attitudes, behaviours and use. London: Office of Communications.

Pan, S. J., Boston, D. J., \& Borcea, C. (2011). Analysis of fusing online and co-presence social networks. Paper presented at the 2011 IEEE international conference on pervasive computing and communications workshops (PERCOM workshops). USA: Seattle.

Rinaldo, S. B., Tapp, S., \& Laverie, D. A. (2011). Learning by tweeting: Using twitter as a pedagogical tool. Journal of Marketing Education, 33(2), 193-203.

Sadri, A. M., Hasan, S., Ukkusuri, S. V., \& Cebrian, M. (2020). Exploring network properties of social media interactions and activities during hurricane Sandy. Transportation Research Interdisciplinary Perspectives, 6, 100143. https://doi.org/10.1016/j.trip.2020.100143.

Siemens, G. (2006). Knowing knowledge. Morrisville, NC: Lulu.

Solis, B. (2010). Behaviorgraphics humanise the social web. Brian Solis: Resource document https://www. briansolis.com/2010/03/behaviorgraphics-humanize-the-social-web/. Accessed March 52015.

Solis, B. (2011). The end of business as usual: Rewire the way you work to succeed in the consumer revolution. Hoboken, NJ: John Wiley \& Sons.

Solis, B., \& Breakenridge, D. K. (2009). Putting the public Back in public relations: How social media is reinventing the aging business of PR. Upper Saddle River, NJ: FT Press.

Tu, C., \& Marina McIsaac, M. (2002). The relationship of social presence and interaction in online classes. The American Journal of Distance Education, 16(3), 131-150.

UNESCO. (2019). Teaching and learning with twitter. Paris: UNESCO.

Veronica, P., Silvia, M., \& Lavinia, P. A. (2018). Traditional versus online marketing for B2B organisations: Where the line blurs. Ovidius University Annals, Economic Sciences Series, 18(1), 382-387.

Visvizi, A., Jussila, J., Lytras, M. D., \& Ijäs, M. (2020). Tweeting and mining OECD-related microcontent in the post-truth era: A cloud-based app. Computers in Human Behavior, 107, 105958. 
Warren, S. J., \& Wakefield, J. S. (2013). Learning and teaching as a communicative action: Social media as educational tool. In K. K. J. Seo (Ed.), Using social media effectively in the classroom (pp. 98-114). New York: Routledge.

Yoshida, M., \& Thammetar, T. (2015). Analysis of an online community of an international cultural project. Advanced Science Engineering and Medicine, 7(7), 550-556. https://doi.org/10.1166/asem.2015.1728.

Yoshida, M., \& Thammetar, T. (2017). Potential possibilities of enhancing online communication of educators in conferences. PEOPLE: International Journal of Social Sciences, 3(2), 2075-2095. https://doi.org/10. 20319/pijss.2017.32.20752095.

Publisher's note Springer Nature remains neutral with regard to jurisdictional claims in published maps and institutional affiliations. 